\title{
Strategies to improve communication in telementoring in acute care coordination: a scoping review
}

\author{
Lauren A. Hampton, MD \\ Peter Brindley, MD \\ Andrew Kirkpatrick, MD, MHSc \\ Jessica McKee, MSc \\ Julian Regehr, MD \\ Douglas Martin, MD \\ Anthony LaPorta, MD \\ Jason Park, MD, MEd \\ Ashley Vergis, MD, MMedEd \\ Lawrence M. Gillman, MD, \\ MMEd
}

Presented at the Canadian Surgery Forum 2018, Sept. 13-15, 2018,

St. John's, NL

Accepted Jan. 21, 2020

\author{
Correspondence to: \\ L. Gillman \\ University of Manitoba \\ GF439, 820 Sherbrook St \\ Winnipeg MB R3A 1R9 \\ Lawrence.Gillman@umanitoba.ca
}

DOI: $10.1503 /$ cjs.015519
Background: Telementoring facilitates the coordination of advanced medical care in rural, remote or austere environments. Because the interpersonal element of telementoring has been relatively underexplored, we conducted a scoping review to identify strategies to improve communication in telementoring.

Methods: Two independent reviewers searched all English-language articles in MEDLINE and Scopus from 1964 to 2017, as well as reference lists of relevant articles to identify articles addressing telementored interactions between health care providers. Search results were gathered in June 2017 and updated in January 2018. Identified articles were categorized by theme.

Results: We identified 144 articles, of which 56 met our inclusion criteria. Forty-one articles focused on improving dispatcher-directed cardiopulmonary resuscitation (CPR). Major themes included the importance of language in identifying out-of-hospital cardiac arrest and how to provide instructions to enable administration of effective CPR. A standardized approach with scripted questions was associated with improved detection of out-of-hospital cardiac arrest, and a concise script was associated with improved CPR quality compared to no mentoring, unscripted mentoring or more complex instructions. Six articles focused on physician-physician consultation. Use of a handover tool that highlighted critical information outperformed an unstructured approach regarding transmission of vital information. Nine articles examined telementoring in trauma resuscitation. A common theme was the need to establish an understanding between mentor and provider regarding the limitations of the provider and his or her environment.

Conclusion: The available data suggest that standardization coupled with short, concise validated scripts could improve efficacy, safety and engagement. Improvements will require multidisciplinary input, practice and deliberate efforts to address barriers.

Contexte : Le mentorat en ligne facilite la coordination des soins médicaux de pointe dans les environnements ruraux, éloignés ou rudimentaires. Toutefois, le facteur relationnel de ce type d'interaction est resté plutôt sous-exploré. C'est pourquoi nous avons réalisé une revue exploratoire pour dégager des stratégies d'amélioration de la communication en contexte de mentorat en ligne.

Méthodes : Deux réviseurs indépendants ont cherché à recenser les articles portant sur les interactions de mentorat en ligne entre professionnels de la santé parmi tous les articles de langue anglaise publiés entre 1964 et 2017 indexés dans les bases de données MEDLINE et Scopus, ainsi que dans les listes bibliographiques des articles pertinents. Les résultats de recherche ont été recueillis en juin 2017 et actualisés en janvier 2018, et les articles recensés ont été regroupés par thèmes.

Résultats : Nous avons retenu 144 articles, dont 56 répondant à nos critères d'inclusion. De ce total, 41 portaient sur l'amélioration de la réanimation cardiorespiratoire (RCR) dirigée par un répartiteur. Parmi les thèmes principaux, on retrouve l'importance du langage dans l'identification des arrêts cardiaques hors de l'hôpital, ainsi que la manière de fournir des instructions permettant de pratiquer une RCR efficace. Une approche normalisée avec des questions scénarisées a été associée à une meilleure détection des arrêts cardiaques hors de l'hôpital, alors qu'un scénario concis a été associé à une amélioration de la qualité de la RCR comparativement à une approche sans mentorat, avec mentorat non scénarisé ou avec des instructions plus complexes. Six des articles retenus portaient sur la consultation de type médecin-médecin. Ils ont conclu que l'utilisation d'un outil de transfert mettant en évidence l'information importante était plus efficace qu'une approche 


\begin{abstract}
non structurée pour la transmission de renseignements vitaux. Finalement, 9 articles portaient sur le mentorat en ligne en réanimation traumatologique. Un des thèmes communs de ces articles était le besoin d'établir une compréhension mutuelle entre mentors et professionnels en ce qui concerne les restrictions de ces derniers et de leur environnement.
\end{abstract}

Conclusion : Les données disponibles semblent indiquer que la normalisation associée à des scénarios courts, concis et éprouvés pourrait améliorer l'efficacité, la sécurité et l'engagement. Cependant, toute amélioration nécessitera un encadrement multidisciplinaire, de la pratique et des efforts délibérés pour surmonter les obstacles.

$\mathbf{M}$ edical telementoring refers to remote guidance of a novice medical provider by an expert over distance. ${ }^{1}$ Advances in information technology mean that telementoring is an increasingly attractive way to provide advanced medical care to rural, remote and austere environments. ${ }^{2,3}$ Rather than discuss the use of telemedicine to facilitate the care of patients whose condition is stable by distant specialists, we focus on telementoring to improve acute care wherever major injury, illness or conflict occurs, and regardless of whether the responder has any medical training. Telementoring has been shown to augment ultrasonography assessment, trauma resuscitation and advanced surgical procedures, despite thousands of miles of separation between expert and provider. ${ }^{4-12}$

Research has heretofore focused on the technologic challenges of telementoring. Despite evidence that nontechnical and nontechnologic factors are among the greatest contributors to medical success or failure,$^{13}$ the interpersonal aspects - specifically, how humans communicate and react - have been comparatively understudied. There is also concern that remote resuscitation can be further hampered by emotional stress, physical barriers (access to the patient) and the loss of nonverbal communication (facial expressions, guiding the hands). Accordingly, we conducted a scoping review to identify strategies that could enhance communication and improve patient rescue over distance. Our objective was to complement the informatic and technical advances in telementoring.

\section{Methods}

\section{Literature search}

We conducted a literature search looking solely at telementored interaction between health care providers; this yielded very limited results. Therefore, the search was expanded, and we used a broad search strategy to capture all available literature that focused on situations in which an expert might be mentoring a relative novice through a medical interaction or procedure over distance. The search included the key terms "remote consultation," "telementoring," "mentoring," "video consultation," "dispatchguided CPR" (cardiopulmonary resuscitation), "bystander CPR," "remote resuscitation" and "distance communica- tion techniques." We searched all English-language articles in MEDLINE and Scopus from 1964 to 2017, as well as reference lists of relevant articles. Search results were gathered in June 2017 and updated in January 2018, with the use of Medical Subject Heading search terms where available, as well as free-text terms in different combinations.

\section{Study selection}

We included studies in the review if they involved telementored interactions between health care providers. This was further defined as any interaction between an experienced health care expert who gave advice and a health care provider who delivered care. We excluded retrieved articles if they were review studies, focused solely on telementoring technology or contained only provider-patient interactions (i.e., telemedicine rather than telementoring).

Two independent reviewers (L.A.H. and L.M.G.) identified relevant articles and categorized the reviews according to theme. A priori, any disagreement regarding inclusion and categorization was resolved by discussion between the reviewers. We graded the included studies using the Grading of Recommendations, Assessment, Development, and Evaluations (GRADE) approach, ${ }^{14}$ with 4 levels of quality of evidence (Table 1).

\section{Results}

We retrieved 144 articles, of which 56 met our inclusion criteria and were included in the review. The search

\begin{tabular}{ll}
$\begin{array}{l}\text { Table 1. Grading of Recommendations, Assessment, } \\
\text { Development and Evaluations (GRADE) approach to assessing } \\
\text { the quality of evidence }\end{array}$ & $\begin{array}{c}\text { Quality } \\
\text { rating }\end{array}$ \\
\hline Methodology & High \\
\hline Randomized trials; double-upgraded observational studies & Moderate \\
\hline $\begin{array}{l}\text { Downgraded randomized trials; upgraded observational } \\
\text { studies }\end{array}$ & Low \\
\hline Double-downgraded randomized trials; observational studies & Very low \\
\hline $\begin{array}{l}\text { Triple-downgraded randomized trials; downgraded } \\
\text { observational studies; case series or reports }\end{array}$ & \\
\hline $\begin{array}{l}\text { *Factors that downgrade studies include risk of bias, limitations within study design, lack } \\
\text { of precision and inconsistency of results. Factors that upgrade studies include large } \\
\text { magnitude of effect or dose-response effect. }\end{array}$ &
\end{tabular}




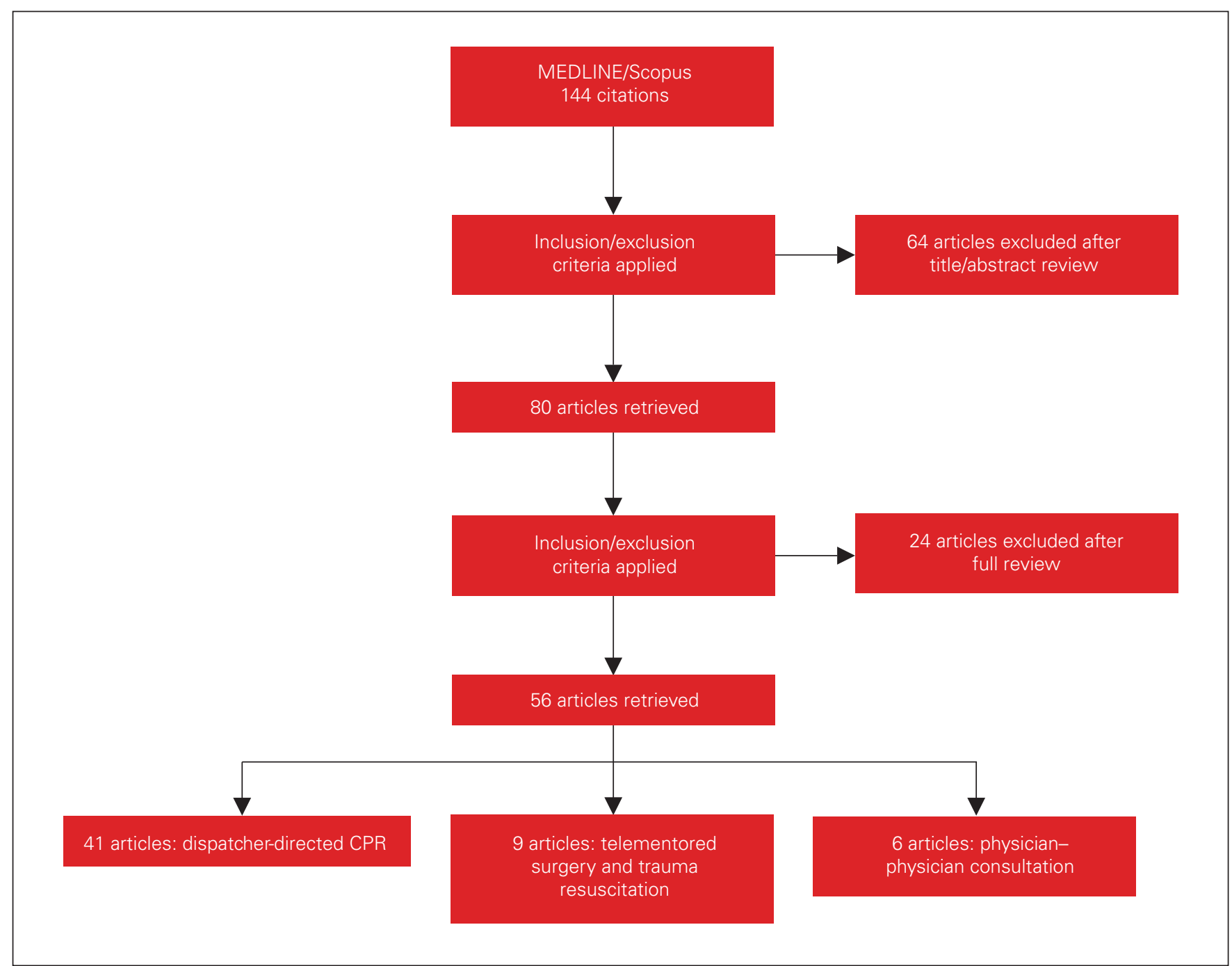

Fig. 1. Flow diagram showing article selection. $C P R=$ cardiopulmonary resuscitation.

process is summarized in Figure 1, and the articles are summarized in Table 2. Of the 56 articles, 41 focused on improving dispatcher-directed CPR, ${ }^{15-55} 6$ focused on physician-physician consultation, ${ }^{56-61}$ and 9 examined telementoring in trauma resuscitation. ${ }^{8,10-12,62-66}$

\section{Dispatcher-directed cardiopulmonary resuscitation}

The articles focusing on improving dispatcher-directed $\mathrm{CPR}^{15-55}$ contained 2 main themes or recommendations: the importance of the dispatcher's identifying an out-ofhospital cardiac arrest, and providing clear instructions to the bystander to administer effective CPR and mitigate barriers. The former articles consisted primarily of retrospective and prospective observational studies. They included experienced dispatchers and used a structured triage tool with prompts to ask for critical information versus a free-form interview. When no structured triage tool was used, crucial questions were often omitted. This occurred up to $50 \%$ of the time ${ }^{44}$ and despite the fact that all dispatchers claimed extensive experience. Articles with the theme of providing clear instructions to the bystander to administer effective CPR and mitigate barriers included randomized controlled trial (RCT) simulations, and prospective and retrospective observational studies, and evaluated the language used in dispatcher-directed CPR. Inclusion of telementoring consistently increased the proportion of bystanders who initiated CPR and improved rates of effective CPR. Simplified instructions improved CPR performance and decreased delays to initiation of CPR. Secondary assessments aimed to identify barriers to the initiation of CPR, including difficult patient access, language barriers and emotional distress.

\section{Physician-physician consultation}

The articles focusing on physician-physician consultation $^{56-61}$ included RCTs and observational studies on the use of a structured handover tool and the use of multimodal communication in the transfer of patient 
Table 2 (part 1 of 2). Summary of included studies

\begin{tabular}{|c|c|c|c|c|c|}
\hline Study & Method & Sample size & Outcome(s) & Relevant findings & $\begin{array}{l}\text { GRADE } \\
\text { rating }\end{array}$ \\
\hline \multicolumn{6}{|c|}{ Improving dispatcher-directed cardiopulmonary resuscitation } \\
\hline Bakke et al., ${ }^{15} 2017$ & $\begin{array}{l}\text { Prospective } \\
\text { observational }\end{array}$ & 311 & $\begin{array}{l}\text { First aid measures } \\
\text { attempted }\end{array}$ & Low precision in dispatcher advice & Low \\
\hline Birkenes et al., ${ }^{16} 2013$ & Observational & 72 & $\begin{array}{l}\text { Activation of speakerphone } \\
\text { function }\end{array}$ & Standardized instructions & Low \\
\hline Birkenes et al., ${ }^{17} 2014$ & $\mathrm{RCT}$ & 30 & $\begin{array}{l}\text { Time to first compression, } \\
\text { compression quality }\end{array}$ & $\begin{array}{l}\text { Complex instructions resulted in delays } \\
\text { Continuous instructions improved performance }\end{array}$ & Moderate \\
\hline Birkenes et al., ${ }^{18} 2012$ & Observational & 30 & Compression technique & $\begin{array}{l}\text { Continuous dispatcher assistance improved } \\
\text { performance }\end{array}$ & Low \\
\hline Brown et al., ${ }^{19} 2008$ & RCT & 215 & $\begin{array}{l}\text { Time to first compression, } \\
\text { total hands-off time }\end{array}$ & $\begin{array}{l}\text { More complex instructions did not improve } \\
\text { performance }\end{array}$ & High \\
\hline Carter et al., ${ }^{20} 1984$ & Observational & 203 & CPR performance & $\begin{array}{l}\text { Standardized instructions resulted in improved } \\
\text { performance }\end{array}$ & Low \\
\hline Cheung et al., ${ }^{21} 2007$ & Observational & 51 lay & CPR quality metrics & $\begin{array}{l}\text { More complex instructions did not improve } \\
\text { performance }\end{array}$ & Low \\
\hline Dami et al., 222010 & Observational & 264 & Initiation of CPR & $\begin{array}{l}\text { Barriers: not medically appropriate, physical } \\
\text { limitations of caller, emotional distress }\end{array}$ & Low \\
\hline Deakin et al., ${ }^{23} 2007$ & Observational & 50 & CPR quality metrics & $\begin{array}{l}\text { More complex instructions did not improve } \\
\text { performance }\end{array}$ & Low \\
\hline Deakin et al., ${ }^{24} 2010$ & Observational & 19 & CPR initiated & Telementoring increased CPR initiation rates & Low \\
\hline Dias et al., 2007 & $\mathrm{RCT}$ & 117 & CPR quality metrics & Simplified protocol improved CPR performance & High \\
\hline Ertl et al., ${ }^{26} 2007$ & Case-control & 101 & First aid measures & $\begin{array}{l}\text { Multimedia communication improved } \\
\text { performance }\end{array}$ & Very low \\
\hline Fujie et al., ${ }^{27} 2014$ & Observational & 559 & Initiation of CPR & $\begin{array}{l}\text { Lower rates of initiation by family members; } \\
\text { higher rates with telementoring }\end{array}$ & Low \\
\hline Fukushima et al., ${ }^{28} 2016$ & Observational & 1850 & Barriers to CPR & $\begin{array}{l}\text { Emotional distress, patient access and } \\
\text { positioning }\end{array}$ & Low \\
\hline Ghuysen et al., ${ }^{29} 2011$ & $\mathrm{RCT}$ & 110 & CPR quality metrics & $\begin{array}{l}\text { Standardized algorithm improved CPR initiation } \\
\text { and quality }\end{array}$ & Moderate \\
\hline Harve et al., ${ }^{30} 2007$ & $\mathrm{RCT}$ & 54 & CPR quality metrics & $\begin{array}{l}\text { Additional instructions for automated external } \\
\text { defibrillation did not compromise CPR quality }\end{array}$ & Moderate \\
\hline Heward et al., ${ }^{31} 2004$ & $\mathrm{RCT}$ & 100 & $\begin{array}{l}\text { Barriers to implementing } \\
\text { DDCPR }\end{array}$ & $\begin{array}{l}\text { Recognition of cardiac arrest, language } \\
\text { problems, third-party caller }\end{array}$ & Low \\
\hline Langlais et al., ${ }^{32} 2017$ & $\mathrm{RCT}$ & 802 & Barriers to CPR & $\begin{array}{l}\text { Increased odds of overcoming barriers with } \\
\text { multiple bystanders }\end{array}$ & Low \\
\hline Martinage et al., 2013 & Observational & 38 & Barriers to CPR & $\begin{array}{l}\text { Persistence of emotional distress, physical } \\
\text { incapacity }\end{array}$ & Low \\
\hline Meron et al.,34 1996 & Observational & 114 & Barriers to CPR & $\begin{array}{l}\text { Emotional distress not a barrier to delivering } \\
\text { CPR instructions }\end{array}$ & Low \\
\hline Mirza et al., ${ }^{35} 2008$ & $\mathrm{RCT}$ & 332 & CPR quality metrics & $\begin{array}{l}\text { Simplified instructions resulted in improved CPR } \\
\text { performance }\end{array}$ & High \\
\hline $\begin{array}{l}\text { Navarro-Patón et al., } \\
2017\end{array}$ & Observational & 38 & CPR quality metrics & Constant telementoring improved CPR & Low \\
\hline $\begin{array}{l}\text { Nord-Ljungquist et al., } \\
2015\end{array}$ & Observational & 20 & CPR quality metrics & $\begin{array}{l}\text { Standardized algorithm improved CPR initiation } \\
\text { and quality }\end{array}$ & Low \\
\hline O'Neill et al., ${ }^{38} 2007$ & Observational & 145 & CPR quality metrics & $\begin{array}{l}\text { DDCPR improved rates of initiating CPR, but it } \\
\text { was often delayed and of poor quality }\end{array}$ & Low \\
\hline $\begin{array}{l}\text { Rasmussen et al., } \\
2017\end{array}$ & $\mathrm{RCT}$ & 128 & CPR quality metrics & $\begin{array}{l}\text { Scripted protocol with simple instructions, } \\
\text { repetition, encouragement improved CPR }\end{array}$ & Moderate \\
\hline $\begin{array}{l}\text { Shimamoto et al., }{ }^{40} \\
2015\end{array}$ & $\begin{array}{l}\text { Prospective } \\
\text { observational }\end{array}$ & $\begin{array}{c}19669 \\
\text { OHCA calls }\end{array}$ & Initiation of CPR & $\begin{array}{l}\text { DDCPR significantly increased rates of CPR } \\
\text { initiation }\end{array}$ & Low \\
\hline Stipulante et al., ${ }^{41} 2014$ & Observational & 468 & Initiation of CPR & $\begin{array}{l}\text { DDCPR significantly increased rates of CPR } \\
\text { initiation }\end{array}$ & Low \\
\hline van Tulder et al., ${ }^{42} 2014$ & $\mathrm{RCT}$ & 26 & CPR quality metrics & No difference between 2 standardized scripts & Moderate \\
\hline Van Vleet et al., ${ }^{43} 2012$ & $\mathrm{RCT}$ & 519 & CPR quality metrics & $\begin{array}{l}\text { Oversimplification of instructions decreased } \\
\text { CPR quality }\end{array}$ & Low \\
\hline \multicolumn{6}{|c|}{ Recognizing out-of-hospital cardiac arrest } \\
\hline Alfsen et al., ${ }^{44} 2015$ & Observational & 21 & $\begin{array}{l}\text { Recognition of } \mathrm{OHCA} \text {, } \\
\text { thematic analysis }\end{array}$ & $\begin{array}{l}\text { Recognition of OHCA depended on caller } \\
\text { factors }\end{array}$ & Low \\
\hline Bång et al., ${ }^{45} 2000$ & Observational & 99 & Interview time and quality & Important questions omitted in $30 \%$ of cases & Low \\
\hline
\end{tabular}


Table 2 (part 2 of 2). Summary of included studies

\begin{tabular}{|c|c|c|c|c|c|}
\hline Study & Method & Sample size & Outcome(s) & Relevant findings & $\begin{array}{l}\text { GRADE } \\
\text { rating }\end{array}$ \\
\hline Bång et al., ${ }^{46} 2003$ & Observational & 100 & Interview quality & $\begin{array}{l}\text { Critical questions omitted in } 26 \% \text { of cases } \\
\text { Protocol improved detection of } \mathrm{OHCA}\end{array}$ & Low \\
\hline Berdowski et al., 2009 & Observational & 258 & Missed OHCA & $\begin{array}{l}\text { OHCA not recognized in } 29 \% \text { of cases } \\
\text { Critical questions omitted }\end{array}$ & Low \\
\hline Bohm et al., ${ }^{48} 2007$ & Observational & 76 & Missed OHCA & $\begin{array}{l}\text { Misinterpretation of agonal respirations by caller } \\
\text { and dispatcher }\end{array}$ & Low \\
\hline Clegg et al., ${ }^{49} 2014$ & Observational & 47 & $\begin{array}{l}\text { Time to progress through } \\
\text { OHCA protocol }\end{array}$ & $\begin{array}{l}\text { Certain steps required more time and speaking } \\
\text { turns }\end{array}$ & Low \\
\hline Dami et al., ${ }^{50} 2010$ & Observational & 294 & Recognition of $\mathrm{OHCA}$ & $\begin{array}{l}\text { Systematic-approach-initiated CPR in } 69 \% \text { of } \\
\text { eligible cases }\end{array}$ & Low \\
\hline Deakin et al., ${ }^{51} 2017$ & Cohort & 2052 & $\begin{array}{l}\text { Sensitivity and PPV of } \\
\text { National Health Service } \\
\text { Pathways triage protocol }\end{array}$ & $\begin{array}{l}\text { Protocol performed with } 71.3 \% \text { sensitivity, } \\
4.2 \% \text { PPV }\end{array}$ & Low \\
\hline Fukushima et al., 522015 & Cohort & 905 & Recognition of OHCA & $\begin{array}{l}\text { Dispatch protocol modified to decrease } \\
\text { ambiguity }\end{array}$ & Low \\
\hline Hardeland et al., ${ }^{53} 2017$ & Observational & 331 & Recognition of OHCA & $\begin{array}{l}\text { Targeted simulation, education and feedback } \\
\text { significantly improved recognition of } \mathrm{OHCA}\end{array}$ & Low \\
\hline Riou et al., ${ }^{54} 2017$ & Observational & 188 & $\begin{array}{l}\text { Caller response to verb } \\
\text { tense used in triage protocol }\end{array}$ & $\begin{array}{l}\text { Linguistic variations in scripted sentences of } \\
\text { protocol affected efficiency of processing } \\
\text { emergency calls }\end{array}$ & Low \\
\hline Scott et al., ${ }^{55} 2012$ & Observational & 268 & Pulse detection rate & $\begin{array}{l}\text { Expert, scripted instructions allowed detection } \\
\text { of pulse rate by laypersons }\end{array}$ & Low \\
\hline \multicolumn{6}{|c|}{ Physician-physician consultation } \\
\hline Armstrong et al., 561997 & Observational & 120 & Patient transfers & Telecommunication reduced transfers by $50 \%$ & Low \\
\hline $\begin{array}{l}\text { Cunningham et al., }{ }^{57} \\
2012\end{array}$ & RCT & 66 & $\begin{array}{l}\text { Telephone referral } \\
\text { performance }\end{array}$ & $\begin{array}{l}\text { SBAR communication tool improved call impact, } \\
\text { time to first pitch and global rating scores }\end{array}$ & Moderate \\
\hline Mair et al., ${ }^{58} 2011$ & Observational & 33 & No. of transfers & $\begin{array}{l}\text { Videoconferencing decreased transfers } \\
\text { compared to telephone consultation }\end{array}$ & Low \\
\hline Marshall et al., ${ }^{59} 2009$ & RCT & 168 & $\begin{array}{l}\text { Content and clarity of } \\
\text { telephone call referral }\end{array}$ & $\begin{array}{l}\text { ISBAR tool improved communication by junior } \\
\text { clinicians }\end{array}$ & Moderate \\
\hline Pimmer et al., ${ }^{60} 2013$ & $\mathrm{RCT}$ & 42 & $\begin{array}{l}\text { Recall and transfer of } \\
\text { information }\end{array}$ & $\begin{array}{l}\text { Visual adjuncts did not contribute to recall and } \\
\text { retention of verbally information }\end{array}$ & Moderate \\
\hline Rogers et al., ${ }^{61} 2001$ & Observational & 26 & $\begin{array}{l}\text { Transfers of patients with } \\
\text { trauma }\end{array}$ & $\begin{array}{l}\text { Teleconsultation enhanced trauma centre- } \\
\text { community relations }\end{array}$ & Low \\
\hline \multicolumn{6}{|c|}{ Telementored assessment and resuscitation } \\
\hline Agarwal et al., ${ }^{62} 2016$ & Case series & 80 & Patient management & $\begin{array}{l}\text { Protocolized care allowed teams to remotely } \\
\text { diagnose, adjust and troubleshoot condition of } \\
\text { critically ill patients }\end{array}$ & Very low \\
\hline Dyer et al., ${ }^{12} 2008$ & Case series & 20 & $\begin{array}{l}\text { Completion of FAST and } \\
\text { EFAST examinations }\end{array}$ & $\begin{array}{l}\text { Instructions given sequentially in simple, } \\
\text { nontechnical language improved performance }\end{array}$ & Very low \\
\hline Gerhardt et al., ${ }^{63} 2014$ & $\mathrm{RCT}$ & 34 & $\begin{array}{l}\text { Completion of life-saving } \\
\text { interventions }\end{array}$ & $\begin{array}{l}\text { Telementoring improved accuracy and speed in } \\
\text { completing critical actions }\end{array}$ & Moderate \\
\hline Kirkpatrick et al., ${ }^{10} 2016$ & $\mathrm{RCT}$ & 101 & $\begin{array}{l}\text { Accuracy of free fluid } \\
\text { detection }\end{array}$ & $\begin{array}{l}\text { Paralleled traditional mentoring with continuous } \\
\text { audio and video communication }\end{array}$ & High \\
\hline Lee et al., ${ }^{11} 2017$ & $\begin{array}{l}\text { Randomized } \\
\text { crossover }\end{array}$ & 30 & $\begin{array}{l}\text { Rate of success in } \\
\text { identifying appendix }\end{array}$ & $\begin{array}{l}\text { Novice onsite practitioners able to perform } \\
\text { ultrasonography as effectively as they could } \\
\text { under onsite mentoring }\end{array}$ & Low \\
\hline McBeth et al., ${ }^{8} 2013$ & Observational & 19 & Ultrasonographic images & Easy or very easy to follow experts' instructions & Low \\
\hline Sibert et al., ${ }^{64} 2008$ & Case series & 16 & $\begin{array}{l}\text { User satisfaction with } \\
\text { interaction, transmission } \\
\text { and image resolution }\end{array}$ & $\begin{array}{l}\text { All mentors felt they could assist with intubation } \\
\text { using video laryngoscopy; } 89 \% \text { would not be } \\
\text { confident with audio alone }\end{array}$ & Very low \\
\hline Stevanovic et al., ${ }^{65} 2017$ & $\begin{array}{l}\text { Randomized } \\
\text { open-label 2-arm } \\
\text { parallel-group } \\
\text { sequential } \\
\text { noninferiority trial }\end{array}$ & $\begin{array}{l}\text { Currently } \\
\text { enrolling }\end{array}$ & $\begin{array}{l}\text { System-induced adverse } \\
\text { events }\end{array}$ & Study ongoing & High \\
\hline Zeger et al., ${ }^{66} 2015$ & Observational & 16 & $\begin{array}{l}\text { Time to intubation, success } \\
\text { rate }\end{array}$ & $\begin{array}{l}\text { Lower success rate with off-site mentoring } \\
\text { Language barrier perceived to be a factor }\end{array}$ & Low \\
\hline
\end{tabular}


information. A handover tool that highlighted critical information outperformed an unstructured approach in the delivery of pertinent information. A combination of audio and visual feedback improved the sense of team cohesion between services, and improved information recall and transfer efficiency.

\section{Trauma resuscitation}

The articles examining trauma resuscitation ${ }^{8,10-12,62-66}$ included case series, RCTs and observational studies. Advanced surgical procedures, including laparoscopic surgery, were conducted successfully with the use of a common language between mentor and on-site mentee. Video conferencing and telestration technology were felt to improve communication on subjective evaluation by the participants. Telementoring in trauma resuscitation improved team performance in terms of faster initiation and completion of life-saving interventions.

\section{Discussion}

Our scoping review showed a concerning relative dearth of publications addressing the interpersonal challenges when relative strangers attempt to resuscitate over distance. To some, dispatcher-directed CPR may seem different, but it has many similarities with telementoring and teleresuscitation. Dispatcher-directed CPR currently accounts for the bulk of research in this area and therefore offers a useful starting point for future research. From the 56 articles identified, we conclude what may seem intuitive but has not been sufficiently emphasized: communication is a vital medical skill and should be deliberate, in terms of both what is said, and how it is understood and carried out. ${ }^{13,67}$ Communication strategies that are standardized, short and concise, and use simple language appear to be better for both mentors and providers. Moreover, communication must not only relay facts but also identify resources and barriers if it is to maximize efficacy and safety. In short, communication should not be left to chance and cannot always be intuited. Just as pilots talk about "flying by voice," medical telementoring involves learning to "resuscitate by voice."13,67 Overall, we believe that the potential of telementoring will be fully realized only when technology is matched by teamwork, and procedural dexterity is matched by "verbal dexterity." 67

The ability of telemedicine to coordinate indirect resuscitation over distance is exciting and potentially life-saving. However, the available literature emphasizes that it is equivalent to interacting face-to-face or conducting a typical telephone call. During telementoring, the mentor needs to convey indirectly not only data but also information and meaning. This then needs to translate rapidly into direct physical action even though the provider is a relative novice or potentially scared, or both. Communication must also be sufficiently robust to make up for the lack of nonverbal communication (e.g., facial gestures and the ability to physically guide the hands of the resuscitator) ${ }^{68}$ When all one has is words, those words take on special significance.

In a study on dispatcher-assisted CPR, Mirza and colleagues ${ }^{35}$ found improvement in average chest compression depth when participants were instructed to "push as hard as you can" instead of "compress the chest $5 \mathrm{~cm}$." In other words, with the use of a structured script rather than freeform communication, the provider delivered better chest compressions and for longer. The studies on dispatcherdirected CPR also emphasize that even the most experienced mentors can omit critical questions. This is concerning given that out-of-hospital cardiac arrest is easier to identify and simpler to address than, for example, complex multisystem trauma. Accordingly, the words chosen are likely even more important when directing more complex or far-forward interventions such as endotracheal intubation, chest tube insertion and damage-control surgery. Our review suggests that there could be value in preemptively scripting each of these procedures. Such scripts should be limited to critical steps, in the correct order, and unnecessary jargon should be avoided. Any script would require input from experts as well from those who are going to carry out the instructions. Scripts would be "fit for task" only once validated by end-users and maintained through realistic ongoing simulations.

Instructions might also need to be modified for language and educational level. For example, children have performed well with remotely mentored ultrasonography using simple "up," "down," "right" and "left" commands. ${ }^{69}$ In contrast, they were baffled by terms such as "parallel" and "rotate." In terms of vocabulary, in the United Kingdom, you are likely to be understood if you say "there's a bloke in the A and E, struck by a lorry on the M5 roundabout," but such language is far less likely to work in North America, even if the details are the same. Those who work in dispatch already have experience giving instructions to a wide variety or recipients and would therefore be key contributors to modifications.

Interestingly, emotional distress was not found to be a major barrier to CPR initiation in our review. Similarly, in a study of simulated remote damage-control surgery by nonphysicians, participants had lower stress (as measured by a post-test survey and heart rate variability) than when they performed the same procedure without guidance.., 70 The most common barriers to CPR initiation were physical limitations, namely, if the provider was unfit to provide aid or the patient was not easily accessed. Extreme environments may hamper access, and remote providers may also have personal connections to the patient. It is therefore important that the mentor understand "what it's like out there" and what state of mind the provider is in in order to provide useful and usable advice. ${ }^{70}$ Taking a few 
moments at the onset of a telementored resuscitation to obtain an understanding of the physical environment, the available resources (both physical and human), the level of training and capabilities of the mentee, and perceived barriers may increase the chance of patient rescue and provider engagement.

\section{Limitations}

Limitations of our review include the paucity of literature in the area of telementoring, the heterogeneity of outcomes and the inherent difficulty with evaluating communication. This prevented a true meta-analysis. The bulk of body of evidence also comes from dispatcher-directed CPR, and, although useful extrapolations can be made, $\mathrm{CPR}$ is simpler and more predictable than other tasks.

\section{Conclusion}

As medicine and technology improve, research into the nontechnical factors of telementoring must keep pace. Communication strategies consisting of standard approaches, short, concise validated scripts using simple language, and systematic identification of available resources and barriers to success have the potential to improve the safety, efficacy and overall experience for mentors and remote providers, and require further study.

Acknowledgement: The authors thank Janet Rothney, Dentistry Librarian, Neil John Maclean Health Sciences Library, University of Manitoba for developing the literature search stradegy.

Affiliations: From the Section of General Surgery, Department of Surgery, University of Manitoba, Winnipeg, Man. (Hampton, Park, Vergis, Gillman); the Section of Critical Care Medicine, Department of Internal Medicine, University of Manitoba, Winnipeg, Man. (Gillman); the Department of Emergency Medicine, University of Manitoba, Winnipeg, Man. (Regehr, Martin); the Department of Critical Care Medicine, University of Alberta, Edmonton, Alta. (Brindley, McKee); the Deparments of Surgery and Critical Care Medicine, University of Calgary, Calgary, Alta. (Kirkpatrick); the Trauma Program, University of Calgary, Calgary, Alta. (Kirkpatrick, McKee); and the Rocky Vista University School of Medicine, Parker, Colo. (LaPorta).

Competing interests: None declared.

Contributors: L. Gillman, P. Brindley, A. Kirkpatrick, D. Martin and A. LaPorta conceived of and designed the study. L. Hampton and L. Gillman acquired the data, which L. Hampton, L. Gillman, P. Brindley, A. Kirkpatrick, J. Regehr, D. Martin, A. LaPorta, J. Park, J. Mckee analyzed and interpreted. L. Hampton wrote the manuscript, which all authors critically revised. All authors gave final approval of the version to be published.

\section{References}

1. Gambadauro P, Torrejon R. The "tele" factor in surgery today and tomorrow: implications for surgical training and education. Surg Today 2013;43:115-22.

2. Kirkpatrick AW, LaPorta A, Brien S, et al. Technical innovations that may facilitate real-time telementoring of damage control surgery in austere environments: a proof of concept comparative evaluation of the importance of surgical experience, telepresence, gravity and mentoring in the conduct of damage control laparotomies. Can 7 Surg 2015;58(3 Suppl 3):S88.

3. Kirkpatrick AW. 2010 Trauma Association of Canada Presidential Address: Why the Trauma Association of Canada should care about space medicine. 7 Trauma 2010;69:1313-22.

4. Ajami S, Lamoochi P. Use of telemedicine in disaster and remote places. 7 Educ Health Promot 2014;3:26.

5. Cubano M, Poulose B, Talamini MA, et al. Long distance telementoring - a novel tool for laparoscopy aboard the USS Abraham Lincoln. Surg Endosc 1999;13:673-8.

6. Kirkpatrick AW, McKee LJ, McBeth BP, et al. The Damage Control Surgery in Austere Environments Research Group (DCSAERG): a dynamic program to facilitate real-time telementoring/telediagnosis to address exsanguination in extreme and austere environments. $\mathcal{f}$ Trauma Acute Care Surg 2017;83(Suppl 1):S156-63.

7. Nguyen N, Okrainec A, Anvari M, et al. Sleeve gastrectomy telementoring: a SAGES multi-institutional quality improvement initiative. Surg Endosc 2018;32:682-687.

8. McBeth P, Crawford I, Tiruta C, et al. Help is in your pocket: the potential accuracy of smartphone- and laptop-based remotely guided resuscitative telesonography. Telemed 7 E Health 2013;19:924-30.

9. Moore RG, Adams JB, Partin AW, et al. Telementoring of laparoscopic procedures: initial clinical experience. Surg Endosc 1996;10:107.

10. Kirkpatrick AW, McKee I, McKee JL, et al. Remote just-in-time telementored trauma ultrasound: a double-factorial randomized controlled trial examining fluid detection and remote knobology control through an ultrasound graphic user interface display. Am 7 Surg 2016;211:894-902.e1.

11. Lee Y, Kim C, Choi HJ, et al. A feasibility study of telementoring for identifying the appendix using smartphone-based telesonography. $f$ Digit Imaging 2017;30:148-55.

12. Dyer D, Cusden J, Turner C, et al. The clinical and technical evaluation of a remote telementored telesonography system during the acute resuscitation and transfer of the injured patient. 7 Trauma 2008;65:1209.

13. Brindley PG, Reynolds SF. Improving verbal communication in critical care medicine. 7 Crit Care 2011;26:155-9.

14. Schünemann H, Brozek J, Guyatt G, et al. Handbook for grading the quality of evidence and the strength of recommendations using the GRADE approach. Updated October 2013. Available: http:// gdt.guidelinedevelopment.org/app/handbook/handbook.html2013 (accessed 2020 Jan. 15).

15. Bakke HK, Steinvik T, Ruud H, et al. Effect and accuracy of emergency dispatch telephone guidance to bystanders in trauma: post-hoc analysis of a prospective observational study. Scand 7 Trauma Resusc Emerg Med 2017;25:27.

16. Birkenes TS, Myklebust H, Kramer-Johansen J. Time delays and capability of elderly to activate speaker function for continuous telephone CPR. Scand F Trauma Resusc Emerg Med 2013;21:40.

17. Birkenes TS, Myklebust H, Neset A, et al. Quality of CPR performed by trained bystanders with optimized pre-arrival instructions. Resuscitation 2014;85:124-30.

18. Birkenes TS, Myklebust H, Neset A, et al. Video analysis of dispatcher-rescuer teamwork - effects on CPR technique and performance. Resuscitation 2012;83:494-9.

19. Brown TB, Saini D, Pepper T, et al. Instructions to "put the phone down" do not improve the quality of bystander initiated dispatcherassisted cardiopulmonary resuscitation. Resuscitation 2008;76:249-55.

20. Carter WB, Eisenberg MS, Hallstrom AP, et al. Development and implementation of emergency CPR instruction via telephone. Ann Emerg Med 1984;13:695-700.

21. Cheung S, Deakin CD, Hsu R, et al. A prospective manikin-based observational study of telephone-directed cardiopulmonary resuscitation. Resuscitation 2007;72:425-35. 
22. Dami F, Carron PN, Praz L, et al. Why bystanders decline telephone cardiac resuscitation advice. Acad Emerg Med 2010;17:1012-5.

23. Deakin CD, Cheung S, Petley GW, et al. Assessment of the quality of cardiopulmonary resuscitation following modification of a standard telephone-directed protocol. Resuscitation 2007;72:436-43.

24. Deakin CD, Evans S, King P. Evaluation of telephone cardiopulmonary resuscitation advice for paediatric cardiac arrest. Resuscitation 2010;81:853-6.

25. Dias JA, Brown TB, Saini D, et al. Simplified dispatch-assisted CPR instructions outperform standard protocol. Resuscitation 2007;72: 108-14.

26. Ertl L, Christ F. Significant improvement of the quality of bystander first aid using an expert system with a mobile multimedia device. Resuscitation 2007;74:286-95.

27. Fujie K, Nakata Y, Yasuda S, et al. Do dispatcher instructions facilitate bystander-initiated cardiopulmonary resuscitation and improve outcomes in patients with out-of-hospital cardiac arrest? A comparison of family and non-family bystanders. Resuscitation 2014;85:315-9.

28. Fukushima H, Panczyk M, Spaite DW, et al. Barriers to telephone cardiopulmonary resuscitation in public and residential locations. Resuscitation 2016;109:116-20.

29. Ghuysen A, Collas D, Stipulante S, et al. Dispatcher-assisted telephone cardiopulmonary resuscitation using a Frenchlanguage compression-only protocol in volunteers with or without prior life support training: a randomized trial. Resuscitation 2011;82:57-63.

30. Harve H, Jokela J, Tissari A, et al. Can untrained laypersons use a defibrillator with dispatcher assistance? Acad Emerg Med 2007;14:624-8.

31. Heward A, Donohoe RT, Whitbread M. Retrospective study into the delivery of telephone cardiopulmonary resuscitation to "999" callers. Emerg Med f 2004;21:233.

32. Langlais BT, Panczyk M, Sutter J, et al. Barriers to patient positioning for telephone cardiopulmonary resuscitation in out-of-hospital cardiac arrest. Resuscitation 2017;115:163-8.

33. Martinage A, Penverne Y, Le Conte P, et al. Predictive factors of successful telephone-assisted cardiopulmonary resuscitation. 7 Emerg Med 2013;44:406.

34. Meron G, Frantz O, Sterz F, et al. Analysing calls by lay persons reporting cardiac arrest. Resuscitation 1996;32:23-6.

35. Mirza M, Brown TB, Saini D, et al. Instructions to "push as hard as you can" improve average chest compression depth in dispatcherassisted cardiopulmonary resuscitation. Resuscitation 2008;79:97-102.

36. Navarro-Patón R, Freire-Tellado M, Pavón-Prieto MDP, et al. Dispatcher assisted CPR: Is it still important to continue teaching lay bystander CPR? Am 7 Emerg Med 2017;35:569-73.

37. Nord-Ljungquist $H$, Brännström $M$, Bohm K. Communication and protocol compliance and their relation to the quality of cardiopulmonary resuscitation (CPR): a mixed-methods study of simulated telephone-assisted CPR. Int Emerg Nurs 2015;23:254-9.

38. O'Neill JF, Deakin CD. Evaluation of telephone CPR advice for adult cardiac arrest patients. Resuscitation 2007;74:63-7.

39. Rasmussen SE, Nebsbjerg MA, Krogh LQ, et al. A novel protocol for dispatcher assisted CPR improves CPR quality and motivation among rescuers - a randomized controlled simulation study. Resuscitation 2017;110:74-80.

40. Shimamoto T, Iwami T, Kitamura T, et al. Dispatcher instruction of chest compression-only CPR increases actual provision of bystander CPR. Resuscitation 2015;96:9-15.

41. Stipulante S, Tubes R, El Fassi M, et al. Implementation of the ALERT algorithm, a new dispatcher-assisted telephone cardiopulmonary resuscitation protocol, in non-Advanced Medical Priority Dispatch System (AMPDS) Emergency Medical Services centres. Resuscitation 2014;85:177-81.

42. van Tulder R, Roth D, Havel C, et al. "Push as hard as you can" instruction for telephone cardiopulmonary resuscitation: a randomized simulation study. 7 Emerg Med 2014;46:363-70.
43. Van Vleet LM, Hubble MW. Time to first compression using Medical Priority Dispatch System compression-first dispatcher-assisted cardiopulmonary resuscitation protocols. Prehosp Emerg Care 2012; 16:242-502.

44. Alfsen D, Møller TP, Egerod I, et al. Barriers to recognition of outof-hospital cardiac arrest during emergency medical calls: a qualitative inductive thematic analysis. Scand 7 Trauma Resusc Emerg Med 2015;23:70.

45. Bång A, Herlitz J, Holmberg S. Possibilities of implementing dispatcher-assisted cardiopulmonary resuscitation in the community: an evaluation of 99 consecutive out-of-hospital cardiac arrests. Resuscitation 2000;44:19-26.

46. Bång A, Herlitz J, Martinell S. Interaction between emergency medical dispatcher and caller in suspected out-of-hospital cardiac arrest calls with focus on agonal breathing. A review of 100 tape recordings of true cardiac arrest cases. Resuscitation 2003;56:25.

47. Berdowski J, Beekhuis GPF, Zwinderman WA, et al. Importance of the first link: description and recognition of an out-of-hospital cardiac arrest in an emergency call. Circulation 2009;119:2096-102.

48. Bohm K, Rosenqvist M, Hollenberg J, et al. Dispatcher-assisted telephone-guided cardiopulmonary resuscitation: an underused lifesaving system. Eur 7 Emerg Med 2007;14:256-9.

49. Clegg GR, Lyon RM, James S, et al. Dispatch-assisted CPR: Where are the hold-ups during calls to emergency dispatchers? A preliminary analysis of caller-dispatcher interactions during out-of-hospital cardiac arrest using a novel call transcription technique. Resuscitation 2014;85:49-52.

50. Dami F, Fuchs V, Praz L, et al. Introducing systematic dispatcherassisted cardiopulmonary resuscitation (telephone-CPR) in a nonAdvanced Medical Priority Dispatch System (AMPDS): implementation process and costs. Resuscitation 2010;81:848-52.

51. Deakin CD, England S, Diffey D, et al. Can ambulance telephone triage using NHS Pathways accurately identify paediatric cardiac arrest? Resuscitation 2017;116:109-12.

52. Fukushima H, Imanishi $M$, Iwami T, et al. Implementation of a dispatch-instruction protocol for cardiopulmonary resuscitation according to various abnormal breathing patterns: a populationbased study. Scand 7 Trauma Resusc Emerg Med 2015;23:64.

53. Hardeland C, Skåre C, Kramer-Johansen J, et al. Targeted simulation and education to improve cardiac arrest recognition and telephone assisted CPR in an emergency medical communication centre. Resuscitation 2017;114:21-6.

54. Riou M, Ball S, Williams TA, et al. 'Tell me exactly what's happened': when linguistic choices affect the efficiency of emergency calls for cardiac arrest. Resuscitation 2017;117:58-65.

55. Scott G, Clawson J, Rector M, et al. The accuracy of emergency medical dispatcher-assisted layperson-caller pulse check using the Medical Priority Dispatch System protocol. Prehosp Disaster Med 2012;27:252.

56. Armstrong IJ, Haston WS. Medical decision support for remote general practitioners using telemedicine. 7 Telemed Telecare 1997;3:27-34.

57. Cunningham NJ, Weiland TJ, van Dijk J, et al. Telephone referrals by junior doctors: a randomised controlled trial assessing the impact of SBAR in a simulated setting. Postgrad Med f 2012;88:619.

58. Mair F, McClusky C, Wilsgaard T, et al. The added value of video for consultations in telemedicine for minor injuries work. 7 Telemed Telecare 2011;17:427-31.

59. Marshall S, Harrison J, Flanagan B. The teaching of a structured tool improves the clarity and content of interprofessional clinical communication. Qual Saf Health Care 2009;18:137.

60. Pimmer C, Mateescu M, Zahn C, et al. Smartphones as multimodal communication devices to facilitate clinical knowledge processes: randomized controlled trial. 7 Med Internet Res 2013;15:e263.

61. Rogers FB, Ricci M, Caputo M, et al. The use of telemedicine for real-time video consultation between trauma center and community hospital in a rural setting improves early trauma care: preliminary results. F Trauma 2001;51:1037-41. 
62. Agarwal AK, Gaieski DF, Perman SM, et al. Telemedicine REsuscitation and Arrest Trial (TREAT): a feasibility study of real-time provider-to-provider telemedicine for the care of critically ill patients. Heliyon 2016;2:e00099.

63. Gerhardt R, Berry J, Mabry RL, et al. Evaluation of contingency telemedical support to improve casualty care at a simulated military intermediate resuscitation facility: the EM-ANGEL study. 7 Spec Oper Med 2014;14:50-7.

64. Sibert K, Ricci MA, Caputo M, et al. The feasibility of using ultrasound and video laryngoscopy in a mobile telemedicine consult. Telemed 7 E Health 2008; 14:266.

65. Stevanovic A, Beckers SK, Czaplik M, et al. Telemedical support for prehospital Emergency Medical Service (TEMS trial): study protocol for a randomized controlled trial. Trials 2017;18:43.

66. Zeger WG, Branecki C, Nguyen T, et al. A description of teaching methods using an on-site instructor versus a distant site instructor to train laryngoscopy to medical students in Hanoi, Vietnam, from Omaha,
Nebraska, by video communication. Int 7 Emerg Med 2015;8:44.

67. Brindley PG, Cardinal P, editors. Optimizing crisis resource management to improve patient safety and team performance: a bandbook for all acute care health professionals. Ottawa: Royal College of Physicians and Surgeons; 2017. Available: https://www.royalcollege.ca/rcsite/ documents/practice-performance-innovation/optimizing-crisis -resource-management-improve-patient-safety-team-performance -e.pdf (accessed 2020 Jan. 15).

68. Wachs JP, Gomez G. Telementoring systems in the operating room: a new approach in medical training. Medicina (B Aires) 2013;73:539-42.

69. McBeth PB, Crawford I, Blaivas M, et al. Simple, almost anywhere, with almost anyone: remote low-cost telementored resuscitative lung ultrasound. F Trauma 2011;71:1528-35.

70. Kirkpatrick AW, Tien TH, LaPorta EA, et al. The marriage of surgical simulation and telementoring for damage-control surgical training of operational first responders: a pilot study. 7 Trauma Acute Care Surg 2015;79:741-7. 